\title{
SOROPREVALÊNCIA DA LEPTOSPIROSE EM FÊMEAS BOVINAS EM IDADE REPRODUTIVA NO ESTADO DE SÃO PAULO, BRASIL
}

\author{
V. Castro" ${ }^{1}$, S.S. Azevedo ${ }^{2}$, T.B. Gotti ${ }^{1}$, C.S.A. Batista ${ }^{1}$, J. Gentili ${ }^{1}$, \\ Z.M. Moraes', G.O. Souza ${ }^{3}$, S.A. Vasconcellos ${ }^{3}$, M.E. Genovez ${ }^{1}$
}

${ }^{1}$ Instituto Biológico, Centro de Pesquisa e Desenvolvimento de Sanidade Animal, Av. Cons. Rodrigues Alves, 1252, CEP 04014-002, São Paulo, SP, Brasil. E-mail: castro@biologico.sp.gov.br

\section{RESUMO}

\begin{abstract}
O presente estudo teve como objetivo determinar a soroprevalência da leptospirose bovina em fêmeas emidade reprodutiva do Estado deSão Paulo, estratificado em sete regiões produtoras. Foram utilizados o delineamento estatístico, as amostras sorológicas e as informações contidas nos questionários empregados no Programa Nacional de Controle e Erradicação da Brucelose e Tuberculose (PNCETB), instituído pelo Ministério da Agricultura, Pecuária e Abastecimento, considerando-se a utilização de fêmeas bovinas com idade $\geq$ a 24 meses (excluindo-se machos), diferentes tipos de produção, práticas de manejo, finalidades de reprodução, tamanho dos rebanhos e sistema de comercialização. Realizou-se a Soroaglutinação Microscópica (SAM) em 8.216 amostras sorológicas de animais provenientes de 1.021 propriedades. De acordo com os resultados obtidos, a infecção por Leptospira spp. ocorre em todo o Estado de São Paulo, com soroprevalência de 49,4\% (IC 95\% = 44,4\%-54,4\%) nas fêmeas bovinas em idade reprodutiva e em $718(71,3 \%$; IC 95\% = 68,5\%-74\%) das propriedades analisadas. O sorovar Hardjo $(46 \%)$ e sua associação com o sorovar Wolffi (21\%) foram prevalentes entre o total de animais sororeagentes, seguidos pelos sorovares Shermani (8,9\%), Autumnalis (4,4\%) e Grippotyphosa (3,9\%). Leptospira spp. está distribuída por todo estado e independe do tipo de exploração, manejo e das práticas de reprodução adotadas nos rebanhos.
\end{abstract}

PALAVRAS-CHAVE: Leptospira spp., fêmeas bovinas, Soroaglutinação Microscópica (SAM), soroprevalência, Estado de São Paulo, Brasil.

\begin{abstract}
SEROPREVALENCEOF BOVINE LEPTOPIROSISIN REPRODUCTIVE-AGEFEMALEBOVINES IN THE STATE OF SÃO PAULO, BRAZIL. The objective of the present study was to determine the seroprevalence of bovine leptopirosis in São Paulo State, stratified in seven cattle production regions. It was based on the statistic delineation, serological samples and responses to the survey employed in the National Program for Control and Eradication of Brucelosis and Tuberculosis established by Ministry of Agriculture (2001). From the herds selected, serological analysis was only conducted on the cows $\geq 24$ months old (excluding the males). The study took into consideration the herd size, the type of productive exploration, the reproductive handling, bovine practices and the commercialization system. The microscopic agglutination test (MAT) was applied on 8,216 serum samples from 1,021 different farms. The results showed that leptospirose infection occurs all over the seven regions of São Paulo State with 49.4\% (CI 95\% $=44.4-54.4 \%$ ) animal seroprevalence and in $718(71.3 \% ; C I 95 \%=68.5-74.0 \%)$ of the herds analyzed. Hardjo $(46 \%)$ was the prevalent serovar for all the animals examined, followed by the Hardjo/Wolffi association $(21 \%)$, Shermani $(8.9 \%)$, Autumnalis (4.4\%) and Grippotyphosa (3.9\%). Leptospira spp. is present in all regions of the State of São Paulo and its occurrence is independent of the handling conditions and reproductive practices adopted in the herds.
\end{abstract}

KEY WORDS: Leptospiraspp., bovine females, microscopic agglutination test (MAT), seroprevalence, São Paulo State, Brazil.

\footnotetext{
${ }^{2}$ Universidade Federal de Campina Grande, Campina Grande, PB, Brasil.

${ }^{3}$ Universidade de São Paulo, Faculdade de Medicina Veterinária e Zootecnia, Departamento de Medicina Veterinária Preventiva e Saúde Animal, Laboratório de Zoonoses Bacterianas, São Paulo, SP, Brasil.
} 


\section{INTRODUÇÃO}

A leptospirose é uma zoonose bacteriana causada por espiroquetas do gênero Leptospira (CÔRTES, 1993). Com vasta distribuição geográfica, é evidenciada em todoomundoeparticularmenteprevalenteempaísesde clima tropical e subtropical, principalmente nos períodos de altos níveis pluviométricos (AcHA;SZYFRES,2001), devido à elevada sobrevivência da bactéria em ambientes úmidos, o que aumenta o risco de exposição e contaminação de animais susceptíveis e seres humanos.

Nos animais de produção, a doença está principalmenterelacionada a problemas reprodutivos como nascimento de animais debilitados, ocorrência de natimortos e abortamentos (FAINE et al., 1999). Nos bovinos, especificamente, as perdas econômicas causadas pela leptospirose estão direta ou indiretamente ligadas às falhas reprodutivas como infertilidade e abortamento, bem como à queda da produção de carnee leite, além de custos com despesas de assistência veterinária, vacinas e testes laboratoriais (FAINE $e t$ al., 1999; VASCONCELLOS, 1996).

Os bovinos são infectados principalmente pelos sorovares Hardjo, Pomona, Grippotyphosa e Icterohaemorrhagiae. O sorovar Hardjo tem sido considerado como o mais adaptado à espécie bovina (Costa et al., 1998). Uma vez introduzido em um rebanho, este sorovar estabelece níveis variáveis de infecção, podendo persistir por longos períodos (Hathaway et al., 1986). Dois genotipos do sorovar Hardjo são encontrados nos ruminantes, o Hardjobovis e o Hardjoprajitno. Hardjobovis ocorre com maior freqüência na Nova Zelândia, Austrália e Holanda (FAINE et al., 1999), sendo eliminado em maiores quantidades pela urina, enquanto que o Hardjoprajitno tem sido relatado no Reino Unido, Nigéria, Índia, Malásia, Brasil, México e nos Estados Unidos da América (Aguiar, 2004).

Para prevenir a doença clínica, as perdas econômicas e minimizar o risco de infecção humana é necessário o controle da leptospirose.

Uma das formas de controle da leptospirose depende da diminuição da prevalência da infecção com sorovares mantidos na população e na diminuição do grau de associação ecológica das leptospiras mantidas por animais de vida livre (HATHAWAY, 1981). Na prática veterinária, baseia-se na vacinação sistemática do rebanho, tratamento de animais doentes com antibioticoterapia, controle dos roedores nas propriedades e eliminação de excesso de água do ambiente (DE NARDI, 2005).

O emprego exclusivo da vacinação tem sido o método de escolha para rebanhos de corte. Muitas vacinas comerciais estão disponíveis no mercado nacional compostas por cinco a dez sorovares, que atendem as soroprevalências da maioria das regiões do país. Por não possuírem papel curativo, seu emprego estaria mais indicado na prevenção da infecção, principalmente de novilhas antes da entrada no serviço reprodutivo (GENOvezet al., 2001b; GeNOvEzet al., 2002; LitTle, 1992; Marshall et al., 1979).

Alguns autores indicam uso de vacinas contra a leptospirose na redução da ocorrência de problemas reprodutivos causados pela variante sorológica Hardjo (Bolin et al., 1989). Porém, o uso da vacinação é um entrave para o diagnóstico sorológico da leptospirose, já que os anticorpos pós-vacinais podem persistir por até seis meses, dificultando a diferenciação de títulos vacinais de reações oriundas de infecção (Freudenstein; HeIn, 1991).

Vários trabalhos realizados no Brasil focaram estudos sorológicos para a leptospirose bovina, entretanto, não avaliaram a soroprevalência no Estado de São Paulo, pois a maioria limitou-se a dados ocasionais e regionais; e ainda mais raros foram aqueles que partiram do planejamento estatístico, considerando amostragem com critérios definidos sobre a população de bovinos. Dessa forma, o objetivo do presente trabalho foi determinar a soroprevalência da leptospirose em fêmeas bovinas emidade reprodutiva no Estado de São Paulo.

\section{MATERIAL E MÉTODOS}

\section{Delineamento amostral}

Para o estudo da soroprevalência da leptospirose no Estado de São Paulo, foram utilizados o delineamento estatístico e as amostras sorológicas empregados no Programa Nacional de Controle e Erradicação da Brucelose e Tuberculose (PNCEBT), instituído pelo Ministério da Agricultura, Pecuária e Abastecimento (BRASIL, 2001).

Para o estudo da brucelose o Estado deSão Paulo foi estratificado em sete circuitos produtores de bovinos, levando-se em consideração os diferentes tipos de produção, as práticas demanejo, as finalidades dereprodução, o tamanho dos rebanhos e o sistema de comercialização, baseando-se nas relações entre os sistemas de produção predominantes nas diferentes áreas geográficas e suas interdependências em relação ao comércio de animais e seus produtos e sub-produtos (Fig. 1). A amostragem foi delineada para a determinação da prevalência de propriedades positivas (focos) e de animais soropositivos para a brucelose bovina em cada estrato e foi realizada em duas etapas: (1) uma seleção aleatória de um número pré-estabelecido de propriedades (unidades primárias); (2) dentro das unidades primárias foi amostrado, aleatoriamente, um número pré-estabelecido de fêmeas bovinas com idade igual ou superior a 24 meses (unidades secundárias). 


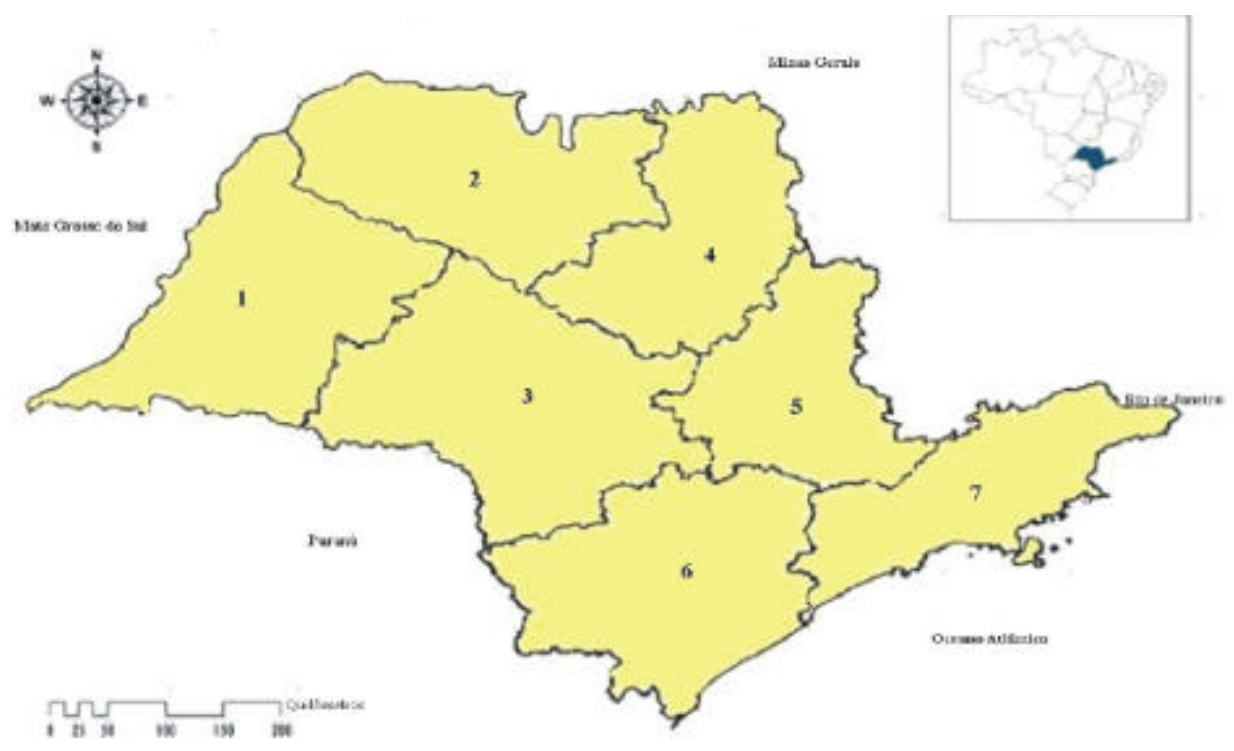

Fig. 1-Circuitos produtores de bovinos no Estado deSão Paulo segundo o Levantamento das Unidades de Produção Agropecuária(LUPA). Coordenadoria de Assistência Técnica Integral (CАTI), 2001.
Para definir o número de propriedades a serem amostradas, utilizou-se o programa EpiInfo versão 6.04, tomando-se os seguintes parâmetros: (a) prevalência esperada de propriedades positivas de $20 \%$; (b) nível de confiança de $95 \%$; e (c) erro absoluto de 6\% (Thrusfield, 1995).

O número de animais a serem testados para um rebanho ser classificado como positivo ou negativo foi calculado com base no valor de sensibilidade e especificidade agregadas (JORDAN, 1996). Dessa forma, o cálculo do número de unidades secundárias foi realizado com o programa Herdacc versão3, de modo a se obter um valor de sensibilidade e especificidade agregadas de pelo menos $90 \%$, utilizando-se os parâmetros: (a) sensibilidade e especificidade dos testes sorológicos, aplicados em nível individual, de 95\% e 99,5\% , respectivamente; (b) prevalência esperada de $20 \%$; e (c) ponto de corte 1 (um).

Como a técnica de soroaglutinação microscópica (SAM), empregada no diagnóstico da leptospirose, é a prova de referência pela Organização Mundial da Saúde (OMS) e apresenta sensibilidade e especificidade elevadas, o delineamento amostral foi extrapolado para a determinação da prevalência de propriedades positivas e animais soropositivos para a leptospirose.

No total, foram visitadas 1.021 propriedades no Estado de São Paulo, com amostragem final de 8.216 fêmeas bovinas com idade igual ou superior a 24 meses.

\section{Diagnóstico sorológico da leptospirose}

O diagnóstico sorológico da leptospirose foi realizado pela técnica de soroaglutinação microscópica (SAM), de acordo com GALTON et al. (1965) e Coloet al. (1973), com uma coleção de antígenos vivos que in- cluiu os sorovares: Castellonis, Javanica, Tarassovi, Whitcombi, Australis, Autumnalis, Bataviae, Bratislava, Canicola, Copenhageni, Grippotyphosa, Hardjo, Hebdomadis, Pomona, Icterohaemorrhagiae, Sentot, Wolffi, Pyrogenes, Butembo, Cynopteri, Panama e Shermani. Os soros foram triados na diluição de 1:100, eaqueles que apresentaram $50 \%$ ou mais de aglutinação foram titulados pelo exame de uma série de diluições geométricas de razão dois. O título do soro foi a recíproca da maior diluição que apresentou resultado positivo. Os antígenos eram examinados ao microscópio de campo escuro, previamente aos testes, a fim de verificar a mobilidade e a presença de auto-aglutinação ou de contaminantes.

\section{Cálculo da soroprevalência}

No animal, o provável sorovar infectante foi o que apresentou o maior título. Na ocorrência de empate sorológico para dois ou mais sorovares, o animal foi desconsiderado da análise, com exceção da associação entre os sorovares Hardjo e Wolffi que, em função da reação cruzada entre eles por pertencerem ao mesmo sorogrupo, foram mantidos na análise.

Na propriedade, o provável sorovar infectante foi o que apresentou o maior título e o maior número de reações positivas. Uma propriedade foi considerada positiva quando nela foi encontrado pelo menos um animal sororeagente.

Foi calculada a prevalência de propriedades positivas e de animais soropositivos para qualquer sorovar e para os sorovares individuais, no Estado de São Paulo e por circuito produtor.

O delineamento amostral para o cálculo da prevalência de animais soropositivos para a leptospirose bovina no Estado de São Paulo empregou uma amostra de grupo estratificada em dois 
estágios, e em cada circuito produtor, uma amostra de grupo em dois estágios (THrusfield, 1995), onde cada propriedade foi considerada um grupo. Os parâmetros utilizados foram: (a) condição do animal (soropositivo ou soronegativo); (b) região a qual pertencia o animal; (c) código do rebanho (para identificar cada grupo); e (d) peso estatístico. O peso estatístico foi calculado conforme fórmula abaixo* (DeAn, 1994).

Para o cálculo da prevalência no Estado de São Paulo, o delineamento amostral empregou a amostra aleatória estratificada (Thrusfield, 1995). Os parâmetros necessários foram: (a) condição da propriedade (rebanho reagente ou não reagente); (b) re- gião a qual pertencia a propriedade; e (c) peso estatístico. O peso estatístico foi determinado aplicando-se a seguinte fórmula (DEAN, 1994):

$$
\text { Peso }=\frac{n^{o} \text { de propriedad es na região }}{n^{o} \text { de propriedad es amostradas na região }}
$$

O cálculo da prevalência de leptospirose bovina por circuito produtor empregou o delineamento amostral de uma amostra aleatória simples, utilizando os parâmetros: (a) número de positivos; e (b) número de propriedades amostradas na região. Todos os cálculos foram realizados com o programa SPSS 13.0 for Windows.

* Fórmula para cálculo de peso estatístico

Peso $=\frac{\text { fêmeas } \geq 24 \text { meses naregião }}{\text { fêmeas } \geq 24 \text { meses nas propriedades amostradas }} \times \frac{\text { fêmeas } \geq 24 \text { meses na propriedade }}{\text { fêmeas } \geq 24 \text { meses amostradasna propriedade }}$

\section{RESULTADOS}

Das 8.216 amostras sorológicas de fêmeas bovinas com idade $\geq$ a 24 meses, 3.338 (49,4\%; IC 95\% = $44,4 \%-54,4 \%)$ foram reagentes naSAM para qualquer um dos 22 sorovares de Leptospira spp., com títulos variando entre 100 e 3.200 . O circuito produtor 3 apresentou o maior número de animais reagentes e com títulos mais elevados (58\%; IC 95\% = 51,5\% $64,1 \%)$, seguida pelos circuitos produtores 7, 1, 4, 6, 2 e 5 (Tabela 1). Foram observadas diferenças significativas nas freqüências de fêmeas positivas para pelo menos um sorovar entre os seguintes circuitos produtores: 1 e $5(p<0,001), 2$ e $3(p=0,001), 2$ e $5(p<0,001)$, 3 e $5(p<0,001), 4$ e $5(p<0,001), 5$ e $6(p<0,001)$ e 5 e 7 ( $p<0,001)$.

O sorovar Hardjo (46\%) e sua associação com o sorovar Wolffi (21\%) foram prevalentes entre o total de animais sororeagentes; enquanto os sorovares Shermani, Autumnalis eGrippothyphosa apareceram na seqüência, com 8,9\%,4,4\% e 3,9\%, respectivamente. A associação dos sorovares Hardjo e Wolffi praticamente ocorreu em todos os circuitos produtores do Estado, freqüentemente com títulos empatados ou com diferença de título correspondente a uma diluição acima ou abaixo. A freqüência do sorovar Wolffi isoladamente mostrou-se inferior a de Hardjo (Tabela 2).

Dentre as 1.021 propriedades investigadas, 718 $(71,3 \%$; IC 95\% $=68,5 \%-74,0 \%)$ apresentaram pelo menos um animal reagente na SAM para qualquer sorovar (Tabela 3). A maior freqüência de rebanhos positivos ocorreu no circuito produtor 7 (85,4\%; IC $95 \%=76,4 \%-91,4 \%$ ), seguida dos circuitos produtores 2, 1, 4, 3, 6 e 5. Foram observadas diferenças significativas nas freqüências de propriedades positivas os circuitos produtores 1 e $3(p=0,009), 1$ e 5 (p $<0,001), 1$ e $6(\mathrm{p}=0,005), 2$ e $3(\mathrm{p}=0,006), 2$ e $5(\mathrm{p}<$ $0,001), 2$ e $6(p=0,003), 3$ e $5(p<0,001), 3$ e $6(p<0,001)$, 3 e $7(p=0,003), 4$ e $5(p<0,001), 5$ e $6(p<0,001), 5$ e $7(p<0,001)$ e 6 e $7(p=0,002)$.

Tabela 1 - Soroprevalência para qualquer sorovar de Leptospira spp. em fêmeas bovinas em sete regiões no Estado de São Paulo, durante o período de outubro a dezembro de 2001, São Paulo, 2006.

\begin{tabular}{ccccc}
\hline Região & Fêmeas amostradas & Fêmeas positivas & Prevalência (\%) & IC 95\% (\%) \\
\hline 1 & 1.383 & 610 & 52,1 & $38,1-65,8$ \\
2 & 1.332 & 615 & 43,0 & $35,5-50,7$ \\
3 & 1.401 & 561 & 58,0 & $51,5-64,1$ \\
4 & 1.209 & 575 & 50,9 & $41,3-60,4$ \\
5 & 1.110 & 242 & 27,7 & $17,8-40,3$ \\
6 & 1.022 & 384 & 46,0 & $40,8-51,4$ \\
7 & 759 & 351 & 53,5 & $45,5-61,4$ \\
Estado & 8.216 & 3.338 & 49,4 & $44,4-54,4$ \\
\hline
\end{tabular}


Tabela 2 - Sorovares de Leptospira spp. prevalentes nas amostras de fêmeas bovinas reagentes em relação ao total de animais positivos do Estado de São Paulo, durante o período de outubro a dezembro de 2001, São Paulo, 2006.

\begin{tabular}{lrrr}
\hline Sorovar & $\mathrm{N}$ & Freqüência $(\%)$ & IC $95 \%(\%)$ \\
\hline Hardjo & $1.538 / 3.338$ & 46,0 & {$[44,37-47,78]$} \\
Associação Hardjo e Wolffi & $711 / 3.338$ & 21,0 & {$[19,92-22,73]$} \\
Shermani & $300 / 3.338$ & 8,98 & {$[8,04-10,01]$} \\
Autumnalis & $149 / 3.338$ & 4,46 & {$[3,79-5,22]$} \\
Grippotyphosa & $132 / 3.338$ & 3,95 & {$[3,32-4,67]$} \\
Bratislava & $110 / 3.338$ & 3,29 & {$[2,72-3,96]$} \\
Icterohaemorrhagiae & $63 / 3.338$ & 1,88 & {$[1,45-2,41]$} \\
Australis & $55 / 3.338$ & 1,64 & {$[1,01-2,14]$} \\
Pomona & $46 / 3.338$ & $1,83]$ \\
Hebdomadis & $44 / 3.338$ & 1,37 & {$[0,96-1,76]$} \\
Castellonis & $32 / 3.338$ & $0,66-1,35]$ \\
Canicola & $31 / 3.338$ & 0,958 & {$[0,63-1,32]$} \\
Pyrogenes & $25 / 3.338$ & 0,928 & {$[0,48-1,10]$} \\
Wolffi & $23 / 3.338$ & 0,748 & {$[0,44-1,03]$} \\
Tarassovi & $11 / 3.338$ & 0,689 & {$[0,16-0,59]$} \\
Copenhageni & $10 / 3.338$ & 0,329 & {$[0,14-0,55]$} \\
Butembo & $10 / 3.338$ & 0,299 & {$[0,14-0,55]$} \\
Sentot & $7 / 3.338$ & 0,299 & {$[0,08-0,43]$} \\
Panamá & $6 / 3.338$ & 0,209 & {$[0,07-0,39]$} \\
Whitcombi & $4 / 3.338$ & 0,179 & {$[0,03-0,31]$} \\
\hline
\end{tabular}

Tabela 3 - Freqüência de propriedades com pelo menos um animal reagente para qualquer sorovar de Leptospiraspp. nas sete regiões no Estado de São Paulo, durante o período de outubro a dezembro de 2001, São Paulo, 2006.

\begin{tabular}{ccccc}
\hline Região & Propriedades amostradas & Propriedades positivas & Frequência (\%) & IC 95\% (\%) \\
\hline 1 & 148 & 120 & 81,1 & $73,9-86,6$ \\
2 & 166 & 135 & 81,3 & $74,6-86,6$ \\
3 & 160 & 108 & 67,5 & $59,8-74,3$ \\
4 & 153 & 117 & 76,5 & $69,1-82,5$ \\
5 & 171 & 74 & 43,3 & $36,0-50,8$ \\
6 & 134 & 88 & 65,7 & $57,2-73,2$ \\
7 & 89 & 76 & 85,4 & $76,4-91,4$ \\
\hline Estado & 1.021 & 718 & 71,3 & $68,5-74,0$ \\
\hline
\end{tabular}

Tabela 4 - Sorovares de Leptospira spp. prevalentes nas propriedades reagentes em relação ao total de propriedades positivas do Estado de São Paulo, durante o período de outubro a dezembro de 2001, São Paulo, 2006.

\begin{tabular}{|c|c|c|c|c|c|c|c|}
\hline Sorovar & $\mathrm{N}$ & $\begin{array}{c}\text { Freqüência } \\
(\%)\end{array}$ & $\begin{array}{c}\text { IC } 95 \% \\
(\%)\end{array}$ & Sorovar & $\mathrm{N}$ & $\begin{array}{c}\text { Freqüência } \\
(\%)\end{array}$ & $\begin{array}{c}\text { IC 95\% } \\
(\%)\end{array}$ \\
\hline Hardjo & $401 / 718$ & 55,18 & {$[51,42-58,88]$} & Wolffi & $6 / 718$ & 0,99 & {$[0,44-2,19]$} \\
\hline Associação & $144 / 718$ & 20,18 & {$[17,31-23,41]$} & Canicola & $5 / 718$ & 0,86 & {$[0,36-2,07]$} \\
\hline Hardjo/Wolffi & & & & Hebdomadis & $6 / 718$ & 0,71 & {$[0,30-1,68]$} \\
\hline Shermani & $57 / 718$ & 7,97 & {$[6,13-10,31]$} & Icterohaemorrhagiae & $6 / 718$ & 0,67 & {$[0,28-1,57]$} \\
\hline Grippotyphosa & $27 / 718$ & 4,41 & {$[3,05-6,32]$} & Castellonis & $3 / 718$ & 0,32 & {$[0,10-1,03]$} \\
\hline Autumnalis & $22 / 718$ & 3,17 & {$[2,06-4,85]$} & Copenhageni & $2 / 718$ & 0,27 & {$[0,06-1,20]$} \\
\hline Bratislava & $16 / 718$ & 2,22 & {$[1,35-3,65]$} & Pyrogenes & $2 / 718$ & 0,27 & {$[0,06-1,21]$} \\
\hline Australis & $9 / 718$ & 1,39 & {$[0,71-2,70]$} & Butembo & $1 / 718$ & 0,15 & {$[0,02-1,07]$} \\
\hline \multirow[t]{2}{*}{ Pomona } & $9 / 718$ & 1,02 & {$[0,51-2,04]$} & Whitcombi & $1 / 718$ & 0,13 & {$[0,02-0,94]$} \\
\hline & & & & Sentot & $1 / 718$ & 0,08 & {$[0,01-0,57]$} \\
\hline
\end{tabular}


Na Tabela 4 são apresentados os sorovares prevalentes no total de propriedades positivas do Estado de São Paulo, onde se observam o sorovar Hardjo com 55,18\% (IC 95\% = 51,42\% - 58,88\%), sua associação com o sorovar Wolffi com 20,18\% (IC 95\% $=17,31 \%-23,41 \%$ ), seguidos pelos sorovaresShermani e Grippothyphosa, respectivamente com 7,97\% (IC $95 \%=6,13 \%-10,31 \%$ ) e $4,41 \%$ (IC $95 \%=3,05 \%$ $6,32 \%)$.

\section{DISCUSSÃO}

As vacinas disponíveis no mercado são bacterinas inativadas baseadas na proteção dirigida ao antígeno LPSdasleptospiras, ressaltando-sesuainterferênciana SAMporcerca deseismesesapósa vacinação(DENARDI, 2005; F REUDENSTEIN; HeIN, 1991), o que poderia em algum momento deste estudo ter sido considerada como resposta sorológica positiva, uma vez que a informação de vacinação contra leptospirose não foi investigada. Porém, de acordo com o Mercado Nacional de Vacinas, o comércio de vacinas anti-leptospira encontra-se estagnadoháalgum tempoeem 2005foram vendidas 178.000 doses (MARCHIORI, comunicação pessoal). Para o contingente de bovinos do Estado de São Paulo, de aproximadamente 14.500.000 cabeças, significa cobertura de 1,3\% de doses, provavelmente de baixo impacto sobre a soroprevalência neste estudo.

Aaplicação daSAM para a detecção deanticorpos anti-Leptospira spp. em 8.216 soros de fêmeas bovinas em idade reprodutiva provenientes de 1.021 propriedades do Estado deSão Paulo permitiu a visualização da abrangência e da disseminação da infecção por leptospiras pelo Estado e, principalmente, as sorovariedades prevalentes. A infecção por leptospiras está presente em todos os sete circuitos produtores em que o Estado deSão Paulo foi dividido, em $49,4 \%$ das fêmeas bovinas com idade igual ou superior a 24 meses e em $71,3 \%$ das propriedades amostradas, o que mostra seu caráter endêmico.

Cada sorovar tem um ou mais hospedeiros em diferentes graus de adaptação. Com epidemiologia complexa, que envolve diferentes espécies suscetíveis, grande número de sorovariedades e a presença de fatores ambientais, a leptospirose deve ser estudada respeitando as diferenças regionais (ELLIS, 1984). Neste inquérito, 19 de 22 sorovares contidos na bateria antigênica foram detectados nas amostras sorológicas das fêmeas analisadas e 17 foram evidenciados nos sete circuitos produtores, sendo que o menor número de sorovares detectados nas propriedades ocorreu no circuito produtor 6 (6 sorovares) e o maior número (13 sorovares), no circuito produtor 5 . Neste aspecto, fica clara a importância da abrangência de sorovariedades antigênicas utilizadas na SAM, pois somente desta forma podem ser percebidas as mudanças ou flutuações nos perfis sorológicos de uma população, região ou mesmo país e a correta instituição de vacinas protetoras sorovar-específicas, até que surjam no mercado vacinas recombinantes e gênero-específicas.

Leptospira spp. sorovar Hardjo foi o mais freqüente $(46,0 \%)$ no total de 3.338 animais reatores, seguida por sua associação com o sorovar Wolffi $(21,0 \%)$ e na seqüência pelos sorovares Shermani, Autumnalis e Grippotyphosa, com prevalências de 8,98\%,4,46\% e $3,95 \%$, respectivamente. Similarmente, nas 718 propriedades reagentes, o sorovar Hardjo $(55,18 \%)$ foi o mais prevalente, seguido pela sua associação com o sorovarWolffi (20,18\%), esorovaresShermani (7,97\%), Grippotyphosa (4,41\%) e Autumnalis (3,17\%). A distribuição praticamente homogênea deste sorovar parece ser independente das diferentes condições de cada região, do tipo de exploração do rebanho e das práticas de reprodução, discordante do que referem PRescott et al. (1988), que apontam os rebanhos de exploração de corte como mais suscetíveis a este sorovar do que os rebanhos leiteiros, possivelmente relacionadas às diferenças de manejo.

FÁvero (2000), Genovez et al. (2004), LANGONi et al. (1999) e VASCONCELLOS et al. (1997) verificaram a ocorrência de Leptospira spp. no Estado de São Paulo com a relevante presença do sorovar Hardjo. Nas demais regiões do país, a freqüência de anticorpos antiLeptospira spp. tambéméassinalada pela significante presença do sorovar Hardjo em vários estados do Brasil, como verificaram MAdRUGA et al. (1980), no Mato Grosso do Sul, Araujo et al. (2005), em Minas Gerais, BROD et al. (1994), no Rio Grande do Sul, Oliveira et al. (2001), no Estado de Pernambuco, HoMEM et al. (2001), na Amazônia Oriental, eLiLEMBAum; Souza (2003), no Rio de Janeiro.

Causador de infecções entre bovinos de todo o mundo, o sorovar Hardjo é também relatado como prevalente em rebanhos de outros países. Na Austrália, Milneret al. (1980) determinaram o sorovar Hardjo como o prevalente em $24.8 \%$ da região metropolitana e 56,3\% da região rural. Em Ontário, Canadá,PRESCOTT et al. (1988) verificaram a relação entre a leptospirose e abortamentos assinalando evidências de infecção pelo sorovar Hardjo em 44,2\% dos animais de rebanho de corte e em $8,4 \%$ dos animais de rebanho leiteiro. Na Nigéria, EzeHetal. (1990) analisaram mais de 1.500 soros de bovinos e obtiveram $14,4 \%$ de animais com anticorpos contra Leptospira spp., tendo o sorovar Hardjo $(35,6 \%)$ como o mais prevalente. Recentemente, em 2005, ODONTSETSEGet al. (2005) estudaram a infecção por Leptospira spp. sorovar Hardjo em três regiões da Mongólia em animais de dupla aptidãoe, concordantes com a literatura mundial, concluíram que o sorovar Hardjo apresenta elevada 
prevalência e que sua transmissão naquele país também ocorre entre bovinos. Em contrapartida, na Espanha, Alonso-ANDicoberry et al. (2001) verificaram maior prevalência do sorovar Bratislava, mas também seguida pelo sorovar Hardjo.

Por pertencerem ao mesmo sorogrupo e, portanto, possuírem afinidades antigênicas, os sorovares Hardjo e Wolffi podem ocorrer em associação (FAINE et al.,1999). Esta associação praticamentefoiverificada em todas as regiões do Estado (20,18\%), embora a ocorrência de Wolffi de forma isolada mostrou-se bastante inferior $(0,99 \%)$ à de Hardjo $(55,18 \%)$. O empate sorológico entre Hardjo e Wolffi não foi desconsiderado da análise com o intuito de se conhecer a freqüência de reações cruzadas entre eles e a importância da inclusão dos dois sorovares na bateria antigênica.

SANTA RosA et al. (1969/1970) relataram, em nove anos de estudo sorológico da leptospirose no Instituto Biológico de São Paulo, elevada prevalência do sorovar Wolffi em amostras de bovinos e bubalinos oriundas de vários estados do Brasil. Da mesma forma, reunindo resultados de sete anos de leptospirose neste mesmo instituto,GIORGI et al.(1981) verificaram a prevalência do sorovar Wolffi em amostras sorológicas de bovinos; contudo, o sorovar Hardjo não constava da bateria antigênica de ambos os trabalhos.

Além da presença do sorovar Hardjo, cuja transmissão usualmente ocorre de bovino a bovino, em alguns rebanhos ou regiões poderia estar ocorrendo infecções incidentais pelos outros sorovares, cuja transmissão indireta está ligada ao contato com o meio ambiente contaminado por leptospiras de espécies silvestres ou outras espécies domésticas, principalmente em situações edafoclimáticas tropicais. Cervídeos, capivaras e outras espécies silvestres atuam como reservatórios de Leptospira spp. para os rebanhos ao encontrar o habitat satisfatório. Dentre os sorovares incidentais mais freqüentes destacam-se Icterohamorrhagiae, Pomona e Canicola, pela elevada patogenicidade, causando sintomas clínicos graves como icterícia, hemorragias e morte.

O sorovar Shermani, que aparece como o terceiro mais freqüente, vem reforçar a importância da ampla composição da bateria antigênica. Este sorovar foi isolado pela primeira vez de um roedor (Proechimys semispinosus) no Panamá (Sulzer et al., 1982). No Brasil, há relato de isolamento deste sorovar de roedores no Mato Grosso (Lins; SANTA Rosa, 1976). Em bovinos do Paraná (GIRALDI, 2003) e em Rondônia (Aguiar et al., 2006), este sorovar foi apontado como o terceiro mais freqüente, precedido pelos sorovares Hardjo e Wollfi. Homem et al. (2000), na Amazônia Oriental, também relataram o sorovar Shermani em bovinos seguido pelos sorvares Hardjo e Bratislava.
Em resumo, os levantamentos sorológicos realizados ao longo dos anos em cidades ou regiões do Estado de São Paulo e publicados por diversos autores evidenciaram a presença da Leptospira spp., no entanto, denota-se diferenças nos pontos de corte da SAMadotados e composição da bateria antigênica, os quais podem interferir na comparação dos dados. $\mathrm{O}$ sorovar Hardjo foi o mais prevalente em fêmeas em idade reprodutiva do Estado deSão Paulo, bem como é o mais comumente implicado nos rebanhos bovinos brasileiros à semelhança do que ocorre mundialmente. Entretanto, ainda é necessário o empenho dos pesquisadores e veterinários no sentido de obtenção de isolados de bovinos para que sejam investigados os genótipos de estirpes deste sorovar circulantes nos rebanhos nacionais, enfocando-se a adaptação e interação com o meio ambiente nas condições brasileiras de clima e manejo.

\section{REFERÊNCIAS}

ACHA, P.N.; SZYFRES, B. Zoonosis y enfermidades transmissibles comunes al hombre y a los animals. Bacteriosis y micosis. 3. ed. Washington: OPS, 2001. v.1,398 p.

AGUIAR, D. M. Prevalência de anticorpos anti- neospora caninum, anti-brucella abortus e anti- leptospira spp. em bovinos da zona rural do município de monte negro, rondônia: estudo de possíveis fatores de risco. 2004. 120p. Dissertação (Mestrado) - Instituto de Ciências Biomédicas, Universidade de São Paulo, São Paulo, 2004.

AGUIAR, D.M.; GENNARI, S.M.; CAVALCANTE, G.T.; LABRUNA, M.B.; VASCONCELLOS, S.A.; RODRIGUES, A.A.R.; MORAES, Z.M.; CAMARGO, L.M.A.

Soroprevalence of Leptospira spp. in cattle from Monte Negro municipality, western Amazon. Pesquisa

Veterinária Brasileira, v.26, n.2, p.102-104, 2006.

ALONSO-ANDICOBERRY, C.; GARCIA-PENA, F.J.; PEREIRA-BUENO, J.; COSTAS, E.; ORTEGA-MORA, L.M. Herd-level risk factors associated with Leptospira spp. Seroprevalence in dairy and beef cattle in Spain. Preventive Veterinary Medicine, v.52, p.109-117, 2001.

ARAUJO, V.E.M.; MOREIRA, E.C.; NAVEDA, L.A.B.; SILVA, J.A; CONTRERAS, R.L. Freqüência de aglutininas anti-Leptospira interrogans em soros sanguíneos de bovinos em Minas Gerais, de 1980 a 2202. Arquivos Brasileiros de Medicina Veterinária e Zootecnia, v.57, n.4, p.430-435, 2005.

BOLIN, C.A.; THIERMANN, A.B.; HANDSAKER, A.L.; FOLEY, J.W. Effect of vaccination with a pentavalent leptospiral vaccine on Leptospira interrogans sorovar hardjo type hardjo-bovis infection of a pregnant cattle. American Journal of Veterinary Research, v.50, n.1, p.161$165,1989$. 
BRASIL. Ministério da Agricultura, Pecuária e Abastecimento. Departamento de Defesa Animal. Programa Nacional de Controle e Erradicação da Brucelose e Tuberculose (PNCEBT). Brasília, 2001. Disponível em: <http:// www.agricultura.gov.br/sda/dda/inicial.htm>. Acesso em: 12 nov. 2002.

BROD, C.S.; MARTINS, L.F.S.; NUSSBAUN, J.R.; FEHLBERG, M.F.B.; FURTADO, L.R.I.; ROSADO, R.L.I. Leptospirose bovina na região sul do estado do Rio Grande do Sul. Hora Veterinária, v.14, p.15-20, 1994.

COLE, J.R.; SULZER, C.R.; PULSSELY, P.R. Improved microtechnique for the leptospiral microscopic aglutination. Applied Microbiology, v.5, p.976-980, 1973.

COSTA, M.C.R.; MOREIRA, E.C.; LEITE, R.C.; MARTINS, N.R.S. Avaliação da imunidade cruzada entre Leptospira hardjo e L. wolffi. Arquivo Brasileiro de Medicina Veterinária e Zootecnia, v.50, n.1, p.11-17, 1998.

CÔRTES, J. A. Epidemiologia. Conceitos e princípios fundamentais. São Paulo: Varela, 1993. 227p.

DEAN, A.G. EpiInfo: a word-processing, database and statistic program for public health on IBM-compatible microcomputers. Atlanta: Center for Diseases Control and prevention, 1994. 601p.

DE NARDI, G. Perfil sorológico de anticorpos antiLeptospira spp. em búfalas (Bubalus bubalis) vacinadas com tipos de vacinas comerciais anti-leptospirose (Bacterina e Membrana externa). 2005. Dissertação (Mestrado em Epidemiologia Experimental e Aplicada às Zoonoses) - Faculdade de Medicina Veterinária e Zootecnia, Universidade de São Paulo, São Paulo, 2005.

ELLIS, W.A. Bovine leptospirosis in the tropics: prevalence, pathogenesis and control. Preventive Veterinary Medicine, v.2, p.411-421, 1984.

EZEH, A.O.; ADDO, P.B.; ADESIYUN, A.A.; BELLO, C.S.; MAKIND, A.A. Serological prevalence of bovine leptospirosis in Plateu State, Nigéria. Revue d' Elevage et de Medecine Veterinaire des Pays Tropicau, v.42, n.4, p.505-508, 1990.

FAINE, S.; ADLER, B.; BOLIN, C.; PEROLAT, P. Leptospira and leptospirosis. 2nd. ed. Melbourne: MediSci, 1999. 272p.

FAVERO, A.C.M. Estudo retrospectivo dos exames sorológicos de leptospirose realizados pelo laboratório de zoonoses bacterianas da Faculdade de Medicina Veterinária e Zootecnia da Universidade de São Paulo, no período de 1984 a 1997. 2000. 115f. Dissertação (Mestrado) - Faculdade de Medicina Veterinária e Zootecnia. Universidade de São Paulo, São Paulo, 2000.
FREUDENSTEIN, H.; HEIN, B. Potency of leptospiral vaccines and protection against chronic infection in golden hamsters. Comparative Immunology. Microbiology and Infectious Diseases, v.14, n.3, p.229-234, 1991.

GALTON, M.M.; SULZER, C.R.; SANTA ROSA, C.A.; FIELDS, M.J. Application of a microtechnique to the agglutination test for leptospiral antibodies. Applied Microbiology, v.13, p.81-85, 1965.

Genovez, M.E.; Oliveira, J.C.; Castro, V.; Ferrari, C.I.L.; Sacarcelli, E.; Cardoso, M.V.; Grasso, L.M.P.S. Influência da vacinação na taxa de parição em rebanho Nelore com leptospirose endêmica. In: CONGRESSO BRASILEIRO DE MEDICINA VETERINÁRIA, 28., 2001, Salvador, BA. Anais. Salvador, 2001.

GENOVEZ, M.E.; OLIVEIRA, J.C.; CASTRO, V.; FERRARI, C.I.L.; SCARCELLI, E.; CARDOSO, M.V.; GRASSO, L.M.P.S.; LANÇA NETO, P. Serological profile of a nelore herd presenting endemic leptospirosis and submitted to vaccination. In: WORLD BUIATRIC CONGRESS, 12., 2002, Hannover. Anais. Hannover, 2002.

GENOVEZ, M. E.; OLIVEIRA, J. C .F.; CASTRO, V.; FERRARI, C. I. L.; SCARCELLI, E.; CARDOSO, M.V.; PAULIN, L. M.; LANÇA NETO, P. Serological profile of a nelore herd presenting endemic leptospirosis and submited to vaccination. Arquivos do Instituto Biológico, São Paulo, v.71, n.4, p.411-416, 2004.

GIORGI, W.; TERUYA, J.M.; MACRUZ, R.; GENOVEZ, M.E.; SILVA, A.S.; BorGo, F. Leptospirose em eqüinos: inquérito sorológico e isolamento de Leptospira icterohaemorrhagiae de feto abortado. O Biologico, São Paulo, v.47, n.2, p.47-53, 1981.

GIRALDI, N. Avaliação da infecção por leptospira em fêmeas bovinas enviadas ao abate no Norte do Paraná, através de diferentes técnicas diagnósticas. 2003. 75f. Tese (Doutorado em Epidemiologia Experimental e Aplicada às Zoonoses) - Faculdade de Medicina Veterinária e Zootecnia, Universidade de São Paulo, São Paulo, 2003.

HATHAWAY, S.C.; LITTLE, T.W.A.; PRITCHARD, D.G Problems associated with the serological diagnosis of Leptospira interrogans serovar hardjo infection in bovine populations. Veterinary Record, v.119, p.84-86, 1986.

HOMEM, V.SF.; HEINEMANN, M.B.; MORAES, Z.M.; VIANNA, M.C.B.; SILVA, S.M.; SAKAMOTO, S.M.; PINHEIRO, S.R.; VEIGA, J.B.; LAU, H.D.; QUANZ, D.;TOURRAND, J.F.; FERREIRA, F.; FERREIRANETO, J.S. Leptospirose bovina em Uruará, Município da Amazônia Oriental. Arquivos do Instituto Biológico, São Paulo, v.67, n.1, p.1-8, 2000. 
HOMEM, V.S.F.; HEINEMANN, M.B.; MORAES, Z.M.; VASCONCELLOS, S.A.; FERREIRA, F.; FERREIRA NETO, J.S. Estudo epidemiológico da leptospirose bovina e humana na Amazônia oriental brasileira. Revista da Sociedade Brasileira de Medicina Tropical, v.34, n.2, p.173-180, 2001.

JORDAN, D. Aggregate testing for the evaluation of Johne's disease herd status. Australian Veterinary Journal, v.73, n.1, p.16-19, 1996.

LANGONI, H.; SOUZA, L.C.; SILVA, A.V.; LUVIZOTTO, M.C.R.; PAES, A.C.; LUCHEIS, S.B. Incidence of leptospiral abortion in Brazilian dairy cattle. Preventive Veterinary Medicine, v.40, p.271-275, 1999.

LILENBAUM, W.; SOUZA, G.N. Factors associated with bovine leptospirosis in Rio de Janeiro, Brazil. Research in Veterinary Science, v.75, p.249-251, 2003.

LINS, Z.C.; SANTA ROSA, C.A. Investigações epidemiológicas preliminares sobre leptospiroses em Humboldt, Aripuanã, Mato Grosso. Acta Amazônica, v.6, n.4, p.46-53, 1976.

LITTLE, T.W.A.; HATHAWAY, S.C.; BROUGHTON, E.S.; SEAWRITHT, D. Control of Leptospira Hardjo infection in beef cattle by whole - herd vaccination. Veterinary Record, v.131, p.90-92, 1992.

MADRUGA, C.R.; AYCARDI, E.; PUTT, N. Freqüência de aglutininas anti-leptospira em bovinos de corte da região sul de cerrado do Estado do Mato Grosso. Arquivos da Escola de Veterinária da Universidade Federal de Minas Gerais, v.32, n.2, p.245, 249, 1980.

MARSHALL, R. B.; BROUGHTON, E. S.; HELLSTROM, J.S. Protection of cattle against natural challenge with Leptospira interrogans serovar Hardjo using a Hardjo Pomona vaccine. New Zealand Veterinary Journal, v.27, p.114-116, 1979.

MILNER, A. R.; WILKS, C. R.; CALVERT, K. The prevalence of antibodies to members of Leptospira interrogans in cattle. Australian Veterinary Journal, v.56, p.327-330, 1980.

ODONTSETSEG, N.; SAKODA, Y.; KIDA, H. Serological evidence of the persistence of infection with Leptospira interrogans serovar Hardjo in cattle in Mongólia. Microbiology e Immunology, v.49, n.9, p.865-869, 2005.
OLIVEIRA, A.A; MOTA, R.A.; PEREIRA, G.C.; LANGONI, H.; SOUZA, M.I.; NAVEGANTES, W.A.; SA, M.E. Soroprevalence of bovine leptospirosis in Garanhuns municipal district, Pernambuco State, Brazil Onderstepoort Journal of Veterinary Research, v.68,n.4, p.275-279, 2001.

ORGANIZAÇÃO MUNDIAL DA SAÚDE. Current problems in leptospirosis research. Report of a WHO expert group. WHO. Technology Report Service, v.380, p.1-32, 1967.

PRESCOTT, J. F.; MILLER, R. B.; NICHOLSON, V. M.; MARTIN, S. W.; LESNICK, T. Seroprevalence and Association with abortion of leptospirosis in cattle in Ontário. Canadian Journal Veterinary Research, n.52 p.210-215, 1988.

SANTA ROSA, C.A.; CASTRO,A.F.P.; SILVA, A.S.; TERUYA, J.M. Nove anos de leptospirose no Instituto Biológico. Revista Instituto Adolfo Lutz, v.29/30, p.19-27, 1969/1970.

SULZER, K.; POPE, V.; ROGERS, F. New leptospiral serotypes (serovars) from the Western Hemisphere isolated during 1964 through 1970. Revista Latinoamericana de Microbiologia, v.24, p.15-17, 1982.

THRUSFIELD, M. Veterinary epidemiology. 2. ed. Cambridge: Blackwell Science, 1995. 479p.

VASCONCELLOS, S.A. Leptospirose Animal. In: ENCONTRO NACIONAL EM LEPTOSPIROSE, 3. 1993, Rio de Janeiro. Anais. Rio de Janeiro: 1996. p.62-66.

VASCONCELLOS, S.A.; BARBARINI JUNIOR, O.; UMEHARA, O.; MORAIS, Z.M.; CORTEZ, A.; PINHEIRO, S.R.; FERREIRA, F.; FAVERO, A.C.M.; FERREIRA NETO, J.S. Leptospirose bovina. Níveis de ocorrência e sorotipos predominantes em rebanhos dos Estados de Minas Gerais, São Paulo, Rio de Janeiro, Paraná, Rio Grande do Sul e Mato Grosso do Sul, período de janeiro a abril de 1996. Arquivos do Instituto Biológico, São Paulo, v.64, n.2, p.7-15, 1997.

Recebido em 25/6/07

Aceito em 13/3/08 